\title{
Caracterização da Aprendizagem da Cibercultura na Educação a Distância
}

\section{The Characterization of Cyberculture Learning in Distance Education}

\author{
ID Elaine da Silva Machado' \\ Sergio de Mello Arruda ${ }^{2}$ \\ Darinez Meneghello Passos 3

\begin{abstract}
'Universidade Estadual de Londrina (UEL), Centro de Ciências Exatas, Programa de Pós-Graduação em Ensino de Ciências e Educação Matemática, Londrina, PR, Brasil.

${ }^{2}$ Universidade Estadual de Londrina (UEL), Centro de Ciências Exatas, Departamento de Física, Londrina, PR, Brasil. Autor Correspondente: sergioarruda@uel.br PR, Brasil.
\end{abstract} \\ ${ }^{3}$ Universidade Estadual de Londrina (UEL), Centro de Ciências Exatas, Departamento de Matemática, Londrina,
}

Resumo: Neste artigo apresentamos os resultados de uma investigação que buscou caracterizar a aprendizagem da cibercultura na modalidade de Educação a Distância (EaD), tendo o ciberespaço como meio em que ela ocorre. Os dados foram provenientes de entrevista com um estudante do curso de graduação em Ciências Naturais, na modalidade EaD. Os relatos do aprendiz foram interpretados segundo os procedimentos indicados pela análise de conteúdo, e sob um instrumento constituído por elementos do conceito de configurações de aprendizagem e da cibercultura. Com base nesse instrumento verificamos que a aprendizagem sobre a cibercultura é um conjunto de relações epistêmica, pessoal e social, principalmente do tipo epistêmico-prática, atrelada a elementos do modelo pedagógico e às linhas de força que compõem o primado da $\mathrm{EaD}$. Os resultados apresentados podem ser úteis às discussões acerca do ensino e da aprendizagem na EaD, e da participação da cibercultura nos processos de formação.

Palavras-chave: Cibercultura; Dimensões da aprendizagem; Processo de ensinoaprendizagem; Educação a distância.

Abstract: In this article we present the results of an investigation that sought to characterize the learning of cyberculture in the Distance Education (DE) modality, with cyberspace as the medium where it occurs. The data came from an interview with an undergraduate student, in the distance education modality, in Natural Sciences. The apprentice's reports were interpreted according to the procedures indicated by content analysis, and with an instrument constituted by elements of the concept of learning venues, and of cyberculture. Based on this instrument, we verified that learning about cyberculture was a set of epistemic, personal, and social, mainly of the epistemic-practical type, together with elements of the pedagogical model and the driving forces that make up the primacy of distance education. We consider that the results presented here may be useful in discussions about teaching and learning in distance education, and the participation of cyberculture in educational processes.

Keywords: Cyberculture; Dimensions of learning; Process of learning; Distance education.

Recebido em: 16/01/2020

Aprovado em: 21/11/2020 


\section{Introdução}

Desde o início dos anos 1990, do século passado, o desenvolvimento e a expansão da World Wide Web (www) incentivam o crescimento das tecnologias digitais e a inovação tecnológica, em diversas áreas da sociedade. A partir desse crescimento, inúmeros recursos de aprendizagem podem ser acessados na Web (NATIONAL RESEARCH COUNCIL, 2009).

$\mathrm{Na}$ modalidade de Educação a Distância (EaD), por exemplo, a inserção de tecnologias da informação para a transmissão de dados possibilitou o desenvolvimento do Ambiente Virtual de Aprendizagem (AVA) - um software utilizado pelas instituições de ensino, para disponibilizar o acesso a cursos oferecidos via Web (ALVES, S. R., 2011).

Por meio do acesso ao AVA, e sob uso de ferramentas específicas, aprendizes e professores comunicam-se virtualmente, acessam materiais de diferentes formatos, realizam avaliações e recebem feedback a respeito de seus desempenhos. Esse meio de comunicação virtual, interativo e comunitário é denominado ciberespaço. Dele emerge uma cultura específica: a cibercultura - um conjunto de técnicas, práticas, atitudes, modos de pensar e valores, que oferece elementos para o contínuo desenvolvimento das interações e dos envolvidos (LÉVY, 1999, 2009).

No campo das pesquisas em Educação, uma forma de compreendermos essa cultura, em situações de aprendizagem na EaD, é por meio das análises das manifestações dos aprendizes, sob a perspectiva da relação com o saber e o conceito de configurações de aprendizagem.

O termo configuração de aprendizagem (ARRUDA; PASSOS, 2015) é especialmente útil para a análise da cibercultura na $E a D$, porque possibilita a identificação das inter-relações do aprendiz com as variadas fontes que ele acessa para aprender via web - hardwares, softwares, pessoas, lugares, imagens, sons, atividades, entre outras (MACHADO; ARRUDA; PASSOS, 2019); com o saber, e com a própria aprendizagem (ARRUDA; PASSOS, 2015, 2017).

Como propõe Lévy $(1999,2009)$, ao reconhecermos a existência do ciberespaço e da cibercultura, precisamos explorar suas potencialidades mais positivas, nos planos: econômico; político; cultural; humano. E, dentre essas, os efeitos na Educação, na aprendizagem aberta e à distância.

A partir dessas considerações, neste artigo, apresentamos os resultados de uma investigação que buscou caracterizar a aprendizagem da cibercultura, em uma configuração de aprendizagem, na modalidade de Educação a Distância (EaD), tendo o ciberespaço como meio em que ela ocorre. Os dados são provenientes de entrevista, com um estudante do curso de graduação, na modalidade EaD, em Ciências Naturais.

A fim de elucidar nossas orientações teóricas, apresentamos, a seguir, o conceito de cibercultura, abordando aspectos etimológicos, e a expressão segundo Lévy (1999, 2009). Posteriormente, destacamos as definições de EaD, aspectos históricos, e a ideia de cibercultura na EaD. Por fim, descrevemos a perspectiva da relação com o saber (ARRUDA; PASSOS, 2017; CHARLOT, 2000) e o conceito de configurações de aprendizagem (ARRUDA; PASSOS, 2015). 


\section{Cibercultura: alguns posicionamentos}

A etimologia da palavra cibercultura remete à combinação das palavras cibernética (cybernetics) e cultura (FERIGATO; SILVA; LOURENÇO, 2017). Contudo, a palavra cibernética tem origem grega, francesa e inglesa (ENCYCLOPEDIA..., 2018). Sobre a origem grega, cibernética surge a partir da palavra kybernetikos (bom em dirigir), para designar a arte do timoneiro - aquele que governa o timão das embarcações (ENCYCLOPEDIA..., 2018); a governança, a técnica necessária para governar o timão (kybernetike tekhne) (LOBATO; KENKEL, 2015). Sob a origem francesa, o termo foi apresentado na primeira metade do século XIX, pelo físico francês André-Marie Ampère, para nomear a ciência do controle dos governos. Sob a origem inglesa, a expressão cybernetics surgiu em 1948, no pósSegunda Guerra Mundial, como título do livro publicado pelo matemático americano Norbert Wiener (ENCYCLOPEDIA..., 2018).

Na referida obra, Wiener (1948) definiu a cibernética como a ciência do controle e das comunicações no animal e na máquina. Por isso, a data de sua publicação é considerada a data de nascimento da cibernética, enquanto ciência independente (ENCYCLOPEDIA..., 2018). Segundo Lobato e Kenkel (2015, p. 636-637), "Norbert Wiener revolucionou a computação ao conceber a informação como uma quantidade tão relevante quanto energia e matéria", considerando a comunicação e o controle como seus elementos constitutivos. Para Wiener (1989), a finalidade da cibernética é o desenvolvimento de linguagem e técnicas capazes de tornar os indivíduos aptos para resolver problemas de controle e de comunicação geral.

Atualmente, no campo da filosofia da informação, a cibercultura é definida por Lévy (1999, 2009), de modo geral, como um conjunto de técnicas, práticas, atitudes, modos de pensar e valores que se desenvolvem no ciberespaço, a partir do uso das tecnologias digitais e da comunicação virtual; é a cultura que oferece elementos para a participação ativa dos integrantes no ciberespaço.

O ciberespaço, ou rede, é um meio de comunicação interativo e comunitário, que surge da interconexão mundial de computadores - das possibilidades oferecidas pela internet e pela Web (LÉVY, 2009). "O termo especifica não apenas a infraestrutura material da comunicação digital, mas também o universo oceânico de informações que ela abriga, assim como os seres humanos que navegam e alimentam esse universo" (LÉVY, 1999, p. 15). Portanto, a cibercultura e o ciberespaço estão imbricados e, na medida em que o ciberespaço cresce, a cibercultura desenvolve-se (LÉVY, 2009).

Lévy (2009) defende, dentro dessa discussão, que existem três princípios mutuamente ressonantes, que orientam o crescimento do ciberespaço e da cibercultura: interconexão; comunidade virtual; inteligência coletiva. A interconexão diz respeito à conexão capaz de possibilitar a comunicação entre pessoas e tecnologias, transcendendo as barreiras físicas. Ela atravessa distâncias e fusos horários; fronteiras geográficas e instituições. Quando indivíduos, máquinas e informações estão interconectados, o espaço se torna um canal interativo para a comunicação. O princípio da comunidade virtual diz respeito a um coletivo de indivíduos interconectados, interessados em compartilharem algo em comum, os quais se organizam por meio das tecnologias digitais e interagem em um processo de cooperação ou de troca (LÉVY, 1999). São exemplos, as comunidades virtuais, sistemas de e-mails e fóruns virtuais (LÉVY, 2009). 
A inteligência coletiva é o produto do empenho dos integrantes das comunidades, objetivados a aprimorarem, cada vez mais, os seus saberes acerca daquele interesse comum, melhorando a colaboração entre os integrantes, a ponto de alcançarem a inteligência em coletivo (LÉVY, 2009). À vista disso, toda a comunidade virtual é uma inteligência coletiva em potencial (LÉVY, 1999).

Atualmente, é possível observar que a cibercultura assume especificidades em diferentes atividades da sociedade. Por exemplo, há cibercultura específica para interagir com os amigos, no Facebook; para seguir as notícias sobre a política mundial, no Twitter; para cumprir as tarefas profissionais, via Google Drive; ou as tarefas acadêmicas da EaD, no Ambiente Virtual de Aprendizagem (AVA), entre outras.

Sobre a EaD e a ideia de cibercultura na EaD, discorreremos a seguir.

\section{A EaD e a Cibercultura na EaD}

Segundo a legislação brasileira, a Educação a distância (EaD) é a modalidade educacional em que a mediação didático-pedagógica nos processos de ensino e aprendizagem ocorre com a utilização de meios e tecnologias de informação e comunicação, com pessoal qualificado, com políticas de acesso, com acompanhamento e avaliação específicos, entre outros, e desenvolve atividades educativas por estudantes e profissionais da educação que ocupam lugares e tempos diversos (BRASIL, 2017).

Sob aspectos históricos, os registros sobre a EaD no Brasil têm início antes de 1900, com oferecimento de curso por correspondência para datilógrafos, ministrado por um professor particular. No entanto, o marco oficial é o ano de 1904, com a instalação das Escolas Internacionais, filiais de uma organização americana. Na ocasião, eram oferecidos cursos profissionalizantes, para os setores do comércio e de serviços, ministrados por correspondência, com remessa de materiais didáticos, principalmente transportados com o uso de ferrovias, pelos correios (ALVES, 2007).

Dessa data até 1970, vários programas foram oferecidos por algumas instituições, tendo como método o ensino por correspondência, e, também, por meio do uso do rádio, de materiais impressos, e da televisão. Essa época, delimitada pelos anos 1904 e 1970, é considerada como a primeira geração da EaD no Brasil (ALVES, L., 2011).

A respeito das características da didática de tal geração, observa-se que a aprendizagem está vinculada ao estudo dos conteúdos a partir de materiais impressos, como guias de estudos e de autoavaliação (SILVA, 2016), e de programas de rádio e televisão; a comunicação entre professor e aluno é assíncrona (as mensagens entre os participantes ocorrem em tempos distintos, por exemplo, uma carta, uma gravação de áudio e de vídeo), lenta e limitada às avaliações previstas; as principais demandas dos alunos são os atos de ler, ouvir e assistir; e não há interação do aluno com outros alunos.

Entre as décadas de 1970 e 1980, fundações e organizações adotaram métodos de transmissão via satélite, e uso de materiais impressos, originando a segunda geração da EaD no Brasil. Nesse período, observa-se a realização de videoconferências. Podemse destacar algumas mudanças acerca da didática, em relação à primeira geração. Por exemplo, na segunda geração, a comunicação entre professor e aluno, em ocasiões 
de videoconferências, ocorre de forma síncrona (as mensagens entre os participantes ocorrem ao mesmo tempo, em sincronia, ao vivo) (SILVA, 2016). As principais demandas do aluno são os atos de ler e de assistir e, nas ocasiões de videoconferências, discutir e compartilhar dúvidas e compreensões, em meio a interações com os pares.

A partir desse mesmo período, as Instituições de Ensino Superior (IES) brasileiras adotaram, aos poucos, o uso de novas tecnologias de informação e comunicação (ALVES, 2007), possibilitando o acesso dos conteúdos das aulas via computadores, e recentemente, via tablets, smartphones e notebooks. Esse movimento das novas tecnologias de informação e comunicação originou a terceira geração da EaD no Brasil.

É possível observar algumas mudanças acerca da didática, em relação às gerações anteriores. Por exemplo, na terceira geração, a aprendizagem está relacionada ao estudo dos conteúdos a partir do acesso do aluno às várias tecnologias digitais, como o AVA. A comunicação entre professor e aluno pode ocorrer de modo assíncrono nas modalidades totalmente à distância (EaD 100\% on-line), e de modo síncrono e assíncrono nas modalidades semipresenciais (b-learning); dentre as demandas do aluno destacam-se as ações de conectar-se na Web, ler livros digitais, assistir a videoaulas, pesquisar, e compartilhar dúvidas e informações em fóruns de discussão com outros estudantes e com o tutor (VENDRUSCOLO; BEHAR, 2016).

Para Amantes (2011 apud VENDRUSCOLO; BEHAR, 2016, p. 306), a terceira geração da $\mathrm{EaD}$ "[...] abandonou os processos de aprendizagem essencialmente individuais, autodirigidos e socialmente descontextualizados". Por isso, atualmente, de modo geral, os modelos pedagógicos para EaD apresentam como base quatro linhas de força - o primado da EaD. São elas: a aprendizagem centrada no estudante, o primado da flexibilidade, primado da interação e princípio da inclusão digital.

A aprendizagem centrada no estudante reconhece o aluno como produtor de seus conhecimentos, desenvolve situações de ensino que promovem autonomia, criatividade, capacidade de monitorar sua aprendizagem ao longo da vida, e interação entre os estudantes. O primado da flexibilidade destaca-se pela não coincidência no tempo e no espaço - assincronismo -, para possibilitar a aprendizagem em qualquer lugar e horário. A interação consiste na criação de grupos de discussão para a interação estudante-estudante e aluno-professor. O princípio da inclusão digital prepara os estudantes para o uso das tecnologias e facilita o acesso de adultos sem a desenvoltura para o uso das tecnologias da informação e da comunicação (TIC) (PEREIRA et al., 2007 apud VENDRUSCOLO; BEHAR, 2016).

Entende-se o conceito de modelo pedagógico para EaD como "[...] um sistema de premissas teóricas que representa, explica e orienta a forma como se aborda o currículo e que se concretiza nas práticas pedagógicas e nas interações professor/ aluno/objeto de estudo" (BEHAR, 2009, p. 24). Os elementos que constituem um modelo pedagógico para EaD são:

- arquitetura pedagógica (AP): composta por aspectos organizacionais relativos aos objetivos educacionais, organização da comunidade virtual, os papéis dos envolvidos, o ecossistema de aprendizagem;

- aspectos metodológicos: as atividades, interação e avaliação; 
- aspectos tecnológicos: a definição do ambiente virtual e suas funcionalidades;

- conteúdo: material instrucional, ferramentas, recurso tecnológico, objeto de aprendizagem ou software; e,

- estratégia para aplicação "[...] ato didático que aponta à articulação ao ajuste de uma arquitetura para uma situação de aprendizagem determinada" (BEHAR, 2009, p. 31).

A respeito dos ambientes de aprendizagem da terceira geração, atualmente existem inúmeros AVAs, com potencialidades distintas (BEHAR, 2009). Neste estudo o nosso sujeito de pesquisa faz uso de uma dessas plataformas, denomina Blackboard. Tal plataforma, oferece suporte aos modelos pedagógicos para EaD propostos para modalidades $100 \%$ on-line, e/ou semipresencial, nos quais são consideradas as formas assíncrona e/ou síncrona para a realização das atividades, procedimentos de avaliação, interação/comunicação etc. Dentre as ferramentas oferecidas pela Blackboard, citamos: agenda, conteúdo, chat, fórum de discussão, perguntas e respostas, sistema de e-mail, entrega de trabalhos, sistema de avaliação on-line, relatórios de acompanhamento e de entrega de tarefas.

Devido às características apresentadas a respeito da terceira geração da EaD, é fundamental que professores e alunos usem de forma adequada os hardwares e softwares necessários para acompanhar o curso (BEHAR, 2009). Não obstante, se tal geração se desenvolve no ciberespaço, concerne à aprendizagem da cibercultura. Nesse cenário, as relações dos aprendizes com a cibercultura podem ser analisadas segundo a perspectiva e o conceito que apresentamos a seguir, da relação com o saber (ARRUDA; PASSOS, 2017; CHARLOT, 2000), e de configurações de aprendizagem (ARRUDA; PASSOS, 2015).

\section{As Configurações de Aprendizagem e as Relações com o Saber}

Configuração de aprendizagem é um conceito proposto por Arruda e Passos (2015), para a análise das situações de aprendizagem que envolve diversos ambientes educativos, físicos ou virtuais, sob a perspectiva da relação com o saber. Neste artigo nós avançamos nas considerações teóricas feitas anteriormente, a respeito dessa proposição, aplicando-a à aprendizagem em situação de EaD.

Na perspectiva de relação com o saber, todo sujeito que aprende o faz por meio de relações que estabelece com o saber. Todavia, devido a características antropológicas, como o fato de nascermos em um mundo preexistente e de vivermos em companhia de outros sujeitos, e de relações de poder e desejo, todos somos obrigados a aprender, por toda a nossa existência (CHARLOT, 2000).

O saber é tudo o que precisa ser aprendido, como por exemplo, uma atividade; uma relação de amor, ódio, amizade; o conteúdo escolar; pessoas; comportamentos; valores; objetos a serem manuseados (CHARLOT, 2000), como um computador; e suas inter-relações permeadas por compreensões, sentimentos e valores individuais e coletivos (ARRUDA; LIMA; PASSOS, 2011; ARRUDA; PASSOS, 2015, 2017). Por conseguinte, o saber é, também, a cibercultura, e a relação com a cibercultura é a relação com o saber. 
Para Arruda e Passos (2017), quando estudamos as relações dos sujeitos com o saber, observamos que, embora elas sejam expressas de modos diferentes, ao categorizá-las, elas pertencem a três modalidades de relações: epistêmica, quando fazem referência às compreensões do sujeito a respeito do saber; pessoal, ao destacarem sentimentos a respeito do saber; e social, ao expressarem valores a respeito do saber. Se considerarmos, além disso, que aprender é mudar a relação com o saber (ARRUDA; PORTUGAL; PASSOS, 2018), as três modalidades de relação apresentadas significam que a aprendizagem pode ser percebida em três dimensões: epistêmica, pessoal e social. Em outras palavras, quando um sujeito fala sobre sua aprendizagem, em geral, essa fala pode ser classificada nessas três dimensões - ou ainda - nesses três tipos de aprendizagem.

Em análises a respeito dessas três dimensões temos observado que a aprendizagem de um saber, por um sujeito aprendiz, varia conforme a configuração em que sua aprendizagem ocorre (MACHADO; ARRUDA; PASSOS, 2019). Uma configuração de aprendizagem pode ser definida como uma estrutura triangular (Figura 1), composta por três vértices ou lugares - A (o aprendiz), S (o saber), F (a fonte de saber) - e suas inter-relações.

Figura 1 - Estrutura das configurações de aprendizagem

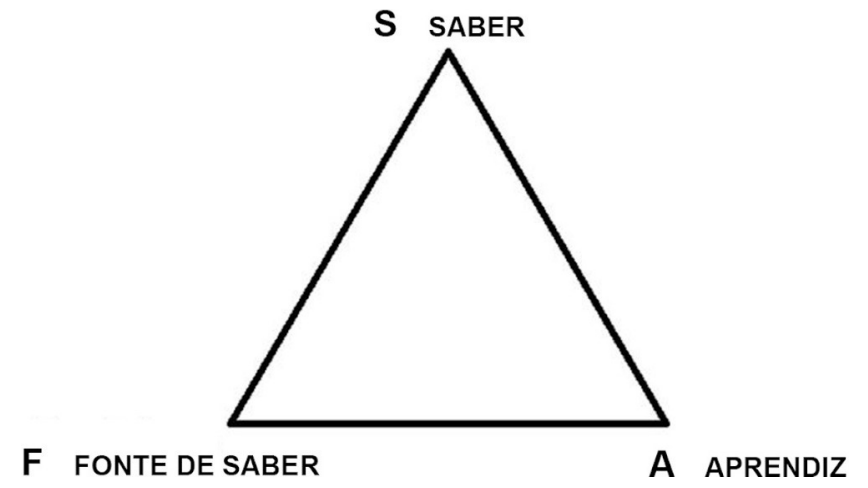

Fonte: Arruda e Passos (2015, p. 11).

Em uma situação concreta, o aprendiz (A) é o sujeito que aprende, e que estabelece relações epistêmicas, pessoais e sociais com a aprendizagem.

O saber (S), como definido em Charlot (2000), é o que precisa ser aprendido pelo aprendiz (A); é subjetivo e objetivo, podendo ser comunicado a outrem.

A fonte de saber (F) é aquilo/aquele que ensina, e pode ser: pessoas (professor, monitor, estudante, comunidade etc.), objetos reais (livro, revista, jornal etc.), objetos mentais ou impressões sensoriais (ideia, imagem, som etc.), plataformas digitais (site, rede social etc.), atividades, relações interpessoais, entre outras. Ou seja, a fonte de saber pode ser humana ou não humana.

Segundo os autores, as análises das relações sob o conceito de configurações de aprendizagem possibilitam identificar, por exemplo, as relações que os aprendizes estabelecem ao aprender em ambientes físicos e virtuais, em situações formais e 
fora da escola; as semelhanças e diferenças observadas nessas situações (MACHADO; ARRUDA; PASSOS, 2019); e as influências que as fontes de saber e o meio exercem sobre a aprendizagem (ARRUDA; PASSOS, 2015). Tais resultados podem contribuir para a compreensão a respeito do ensino praticado pelos professores e a formação docente, a mobilização dos aprendizes em relação à sua aprendizagem, entre outras.

Após esse breve delineamento teórico, descrevemos os procedimentos metodológicos realizados no desenvolvimento desta pesquisa.

\section{Procedimentos Metodológicos}

Realizamos esta investigação por meio de uma abordagem qualitativa, pautando-nos nas definições gerais apresentadas por Bogdan e Biklen (1994), e suas orientações acerca da representatividade da subjetividade dos sujeitos de pesquisa, sob os princípios éticos - de consentimento informado, garantia de anonimato e proteção de danos.

Ao esclarecermos o nosso sujeito de pesquisa acerca de tais princípios, o mesmo escolheu não divulgar o seu nome verdadeiro, junto aos dados publicados. Mas, fez questão de eleger o pseudônimo Horácio para que suas falas tivessem "vida" (expressão utilizada pelo próprio sujeito).

Assim, o nosso sujeito de pesquisa, identificado como Horácio, tem 36 anos, cursa o segundo ano de graduação em Ciências da Natureza em uma instituição privada, na modalidade EaD. A escolha por Horácio se deu pelo fato de ele já ter realizado $50 \%$ do curso e se declarar disposto em compartilhar sua experiência.

Para melhor compreendermos o perfil do aprendiz, apresentamos, nos próximos parágrafos, algumas informações a respeito do modelo pedagógico para EaD (BEHAR, 2009), adotado pela IES do pesquisado para o curso em questão.

O objetivo do curso, na ocasião, era o de habilitar o aluno para o planejamento, a organização e o desenvolvimento de atividades interdisciplinares da área de Ciências Naturais. E estava estruturado em seis módulos, divididos em seis períodos semestrais (3 anos).

Cada módulo era composto por um conjunto de disciplinas, cursadas sob a modalidade EAD $100 \%$ on-line. Por isso, as atividades de aprendizagem eram realizadas pelos alunos exclusivamente via AVA Blackboard. As atribuições do aluno no AVA estavam assim delineadas: acessar as videoaulas e os livros digitais do curso; participar ativamente do fórum de discussão; apresentar comentários sobre os textos complementares; responder aos questionários; enviar projetos; acessar e cumprir o cronograma de atividades; enviar e-mails à secretaria virtual, aos tutores e aos professores; acessar os demais serviços oferecidos pela instituição. A forma de realização dessas atividades era assíncrona, como, por exemplo, a gravação das aulas pelos professores em um momento anterior ao acesso do aluno.

O processo avaliativo ocorria ao final de cada semestre, e, era constituído por provas avaliativas on-line; produção de projeto interdisciplinar; prova avaliativa realizada presencialmente pelo aluno no polo da IES, sem a presença do 
professor / tutor, colegas de classe ou grupos de estudo. As estratégias que compunham o modelo pedagógico eram: comunidades de aprendizagem, projetos interdisciplinares e processo de tutoria pela internet. A aprendizagem estava centrada no estudante, baseada na flexibilidade de acesso à aprendizagem (conteúdos e atividades), na interatividade (entre aprendizes e aprendizes-professor) e na promoção de inclusão digital. Portanto, observava as quatro linhas de força do primado da EaD.

Os dados acerca das relações de Horácio com o saber foram coletados por meio de uma entrevista semiestruturada (FIORENTINI; LORENZATO, 2012), conduzida a partir da questão previamente formulada: Fale-me a respeito de aprender na EaD ${ }^{1}$. E, de questões emergentes, para esclarecimentos a respeito das respostas dadas a esta questão deflagradora: o que você teve de aprender para estudar na EaD? Com relação à sua rotina, como ocorreu sua aprendizagem no AVA? E fora do AVA?

Para realizar as análises, submetemos as respostas apresentadas por Horácio aos procedimentos interpretativos indicados pela análise de conteúdo ( $A C)$, obedecendo às três etapas orientadas por Fiorentini e Lorenzato (2012): a desmontagem dos textos em fragmentos, a organização dos fragmentos em categorias a priori, o estudo das frases para identificar os sentidos e as intenções expressas por Horácio.

$\mathrm{Na}$ etapa de fragmentação realizamos repetidas leituras, a fim de efetuar um levantamento das principais informações apresentadas pelo aprendiz.

Na fase seguinte, de categorização, organizamos as informações em categorias a priori, de acordo com as características comuns. Sobre essas categorias esclarecemos que são provenientes da definição de Lévy (1999), apresentada à cibercultura (técnicas, práticas, atitudes, modos de pensar e valores que se desenvolvem no ciberespaço); das dimensões da aprendizagem (epistêmica, pessoal e social), e dos elementos estruturantes do triângulo das configurações de aprendizagem (aprendiz, saber e fonte de saber), apresentados por Arruda e Passos $(2015,2017)$.

Com base nesses pressupostos, o objetivo deste artigo é apresentar a caracterização da aprendizagem do sujeito da pesquisa (Horácio) sobre cibercultura, em uma configuração que tem a EaD como fonte de saber e o ciberespaço como meio, tendo por base as categorias de Lévy (1999) e as dimensões da aprendizagem.

Ao iniciarmos a categorização dos dados acerca das categorias de Lévy (1999), sentimos a necessidade de diferenciar prática de técnica. Para isso, elaboramos uma definição sintética, a partir do confronto entre as definições apresentadas por Lévy (1999) e os significados atribuídos às expressões, pelo dicionário da língua portuguesa (MICHAELIS, 2018). Tal movimento levou-nos a considerar que: prática é o exercício, a realização, de dada atividade relativa à aprendizagem, sob o uso de tecnologias digitais e comunicação virtual; técnica é o conhecimento aprofundado, acerca da prática exercida para a aprendizagem, sob o uso de tecnologias digitais e comunicação virtual.

${ }^{1} \mathrm{O}$ presente artigo faz parte do projeto de pesquisa intitulado $O$ ensino e a aprendizagem de ciências e matemática em sala de aula e em ambientes informais, coordenado pelo pesquisador Sergio de Mello Arruda, e aprovado pelo Comitê de Ética (Número do CAAE: 57663716.9.0000.5231. Número do Parecer: 1.666.360). 
Ainda na fase de categorização, atribuímos, ao final de cada trecho categorizado, a letra inicial do pseudônimo do aprendiz e um número, (H01, H02...), de modo a identificá-los e tornar possível a menção dos mesmos, em momentos específicos da seção de apresentação dos dados. Segue um exemplo em que citamos o trecho (H05), a respeito da participação do aprendiz no Fórum de discussão: Eu me sinto bem, quando ajudo no Fórum [H05].

Finalizada a categorização, realizamos a última fase procedimental indicada pela AC. Nela, estudamos as frases categorizadas, identificando os sentidos e as intenções atribuídos pelo aprendiz e revisamos a própria análise, fato que culminou nos resultados que trazemos na próxima seção.

\section{Apresentação dos Resultados e Discussões}

Antes de apresentar os resultados é necessário definir a estrutura da configuração na qual ocorreu a aprendizagem de Horácio. Em outras palavras, precisamos deixar claro quem são $\mathrm{S}$ e $\mathrm{F}$ no triângulo da Figura 1, considerando que A é o próprio Horácio.

No caso deste artigo, estamos investigando o que Horácio aprendeu sobre a cibercultura, definida como um conjunto de técnicas, práticas, atitudes, modos de pensar e valores, apontadas por Lévy (1999). Portanto, S é a cibercultura, considerada a partir das cinco categorias de Lévy. Por meio de qual fonte Horácio aprendeu sobre cibercultura? Ele aprendeu por meio da EaD, no ciberespaço. Essa é, portanto, a fonte F, o que nos leva ao triângulo da Figura 2:

Figura 2 - Configuração de aprendizagem para o caso do Horácio

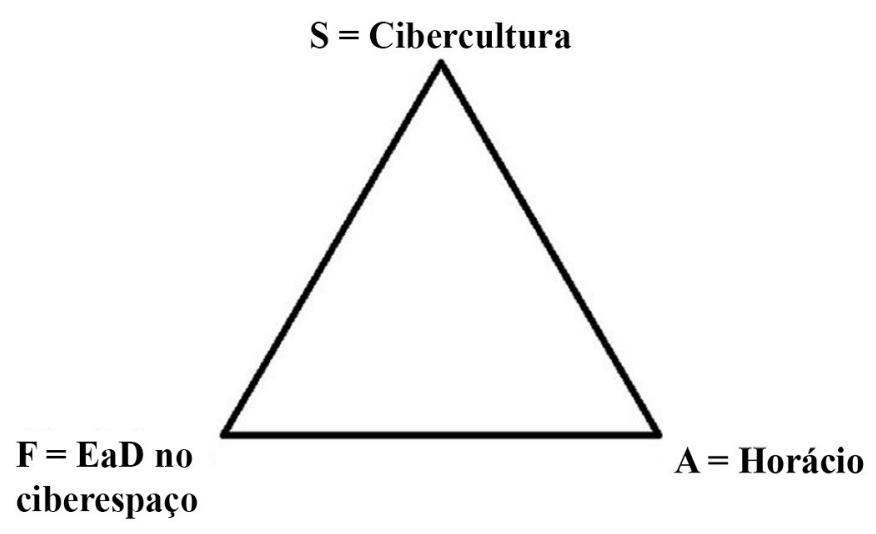

Fonte: elaborada pelo autores.

Considerando, portanto, as cinco categorias a priori, a partir de Lévy (1999) - técnicas, práticas, atitudes, modos de pensar e valores, e as três dimensões da aprendizagem: epistêmica (compreensão), pessoal (sentimentos) e social (valores) podemos elaborar quadros detalhando o aprendizado de Horácio sobre a cibercultura.

O primeiro deles, o Quadro 1, explicita na primeira coluna as manifestações de Horácio a respeito do que foi indagado, e na segunda coluna a caracterização da cibercultura, organizadas por meio das categorias estabelecidas a priori, em função dos teóricos que assumimos para o desenvolvimento da investigação. 


\section{Quadro 1 - Categorização dos relatos de Horácio}

\section{Manifestações de Horácio}

Caracterização da aprendizagem da cibercultura

É bem tranquilo [estudar no sistema EAD] ${ }^{2}$, eu gosto, porque eu aprendo em casa, no meu ritmo. [...], mas com disciplina do tempo, seguindo o calendário [do curso]. [H01]

[Em casa] tenho acesso a tudo que eu preciso. Assisto às aulas no AVA, Dimensão epistêmica relativa à sua aprendizagem, faço exercícios com livros [em PDF], no computador e no celular. [H02]. no que diz respeito às práticas.

Pesquiso, faço todas as atividades que preciso. [H03]

Quando eu tenho dúvidas, ou alguém do Fórum tem e eu tenho que Dimensão social relativa à sua aprendizagem, no ajudar, [...] e fico sabendo [os conteúdos a respeito das Ciências que diz respeito aos valores.

Naturais], posto no Fórum e todos podem aprender. [H04]

Eu me sinto bem quando ajudo no Fórum. [H05]

O professor está lá. Ele lê tudo que a gente escreve, mas dá um tempo para a gente resolver as dúvidas. Quando ninguém consegue, ou fala errado, ele aparece e ajuda. [H06]

Também tem o lado ruim do Fórum. Muita pergunta idiota, mas tudo bem. [H07]

O Fórum sempre contribui com alguma coisa. Pensando bem, não vejo o lado ruim, não tem. [...], é só você parar de ler. [H08]

Algumas pessoas não sabem usar o Fórum, enchem com informações desnecessárias, e você perde o tesão de ler, cansa, irrita. [H09]

Eu saio do Fórum se fico irritado, tomo um café, dou uma volta, depois volto. Faço isso para não falar o que penso e não discutir. [H10]

No cronograma do curso já está definido o que vai ser discutido no Fórum. Tem que fazer comentário sobre os textos complementares. Não é para perguntar de matrícula [...], prova, nada disso. [H11]

Quando conheço pouco o assunto eu leio primeiro o que o pessoal escreveu [para fazer os meus comentários]. Eu aprendo com essas pessoas, com essas respostas que essas pessoas colocam lá. [H12]

[Para realizar as atividades e aprender na EaD, você tem que] saber usar bem o computador, Websites. Quem não sabe apanha muito. Tem que saber o mínimo de navegação Web, para acessar os textos, vídeos; o mínimo de entendimento de como pesquisar no Google. Também, saber fazer downloads e armazenar arquivos no computador, de forma organizada. [...]. Tem que saber usar o Word e Excel, para fazer os trabalhos, no final dos bimestres. Ah, e com [normas] ABNT. Também, para esses trabalhos, tem que saber usar programas de edição de imagens, porque, às vezes, você precisa criar uma imagem, para ilustrar algum ciclo de vida, fluxogramas [...], e tem softwares que te ajudam a fazer isso, igual ao Draw.io. [H13]

Você está sozinho, tem que pesquisar, para as aulas, exercícios, o Fórum. Olhando por esse lado, me parece ser um fator que ajuda no desenvolvimento da capacidade de pesquisa científica também. [H14] Porque é você e Deus, quer dizer, é você e o Google. [H15]
Dimensão pessoal relativa à sua aprendizagem, a respeito das práticas.

Dimensão epistêmica relativa à fonte de saber (professor e demais integrantes), a respeito das práticas.

Dimensão social relativa à fonte de saber (Fórum), a respeito dos valores.

Dimensão epistêmica relativa à fonte de saber (Fórum), no que diz respeito aos modos de pensar. Dimensão pessoal relativa à fonte de saber (Fórum), a respeito das práticas.

Dimensão social relativa à fonte de saber (demais integrantes), no que diz respeito a atitudes.

Dimensão epistêmica relativa à sua aprendizagem, no que diz respeito às práticas.

Dimensão epistêmica relativa à fonte de saber (demais integrantes), no que diz respeito ao modo de pensar.

Dimensão epistêmica relativa ao saber (diversos saberes), no que diz respeito às técnicas.
Dimensão epistêmica relativa à fonte de saber (demais integrantes), no que diz respeito ao modo de pensar.

Dimensão social relativa à fonte de saber (Google), a respeito dos valores.

Fonte: elaborado pelos autores.

\footnotetext{
${ }^{2}$ Os textos entre colchetes foram incluídos para esclarecer alguns fatos a respeito do depoimento, a fim de elucidar a interpretação e alocação que expomos na segunda coluna.

${ }^{3}$ As palavras grifadas na coluna 2 indicam as categorias a priori estabelecidas e ancoradas nos referenciais eleitos para análise, indicando se as dimensões são epistêmicas, pessoais ou sociais, em configurações de aprendizagem em que o destaque é dado ao saber, à fonte de saber ou à própria aprendizagem do aprendiz; considerando para estabelecer essas interações, as técnicas, as práticas, as atitudes, os modos de pensar, e os valores.
} 
A interpretação e organização dos relatos apresentados por Horário possibilitaram a caracterização da cibercultura, sob as considerações que trazemos nos próximos parágrafos, em complementação aos resultados explicitados na coluna 2 do quadro anterior.

Para elaborar nossas argumentações consideramos a configuração de aprendizagem como estrutura básica, passando a analisar os dados obtidos por meio dos relatos de Horácio, acerca dos três vértices da Figura 2: A (Horácio), S (cibercultura) e $\mathrm{F}$ (EaD no ciberespaço). Em seguida, elaboramos quadros que sintetizam os relatos de Horácio, distribuídos nas colunas relativas às cinco categorias de Lévy (1999), e nas linhas referentes às dimensões epistêmicas, pessoais e sociais da aprendizagem.

\section{Vértice A: aprendiz, aprendizagem}

Do ponto de vista epistêmico, Horácio apresenta suas reflexões e compreensões a partir do vértice $A$ (enquanto aprendiz), destacando as práticas empregadas, via hardwares, para aprender no ciberespaço. Entre elas elenca: o acesso às aulas no AVA; a resolução de exercícios on-line; atividades de leitura; participação na comunidade virtual; pesquisas na Web; demais atividades relativas à elaboração de trabalhos acadêmicos (tais relatos podem ser confirmados em H02, H03, H11). Também expressa seus modos de pensar sobre as colaborações que a prática de pesquisa na Web, sem o acompanhamento de professores, pode proporcionar para o desenvolvimento acadêmico $(\mathrm{H} 14)$.

Do ponto de vista pessoal, no que diz respeito ao vértice $A$, Horácio apresenta seus sentimentos como aprendiz, enfatizando seu gosto, sua tranquilidade e seu bemestar, a respeito de estudar em casa, por meio de práticas de uso das tecnologias digitais (H01); o gosto por auxiliar os outros integrantes em suas dúvidas, por meio de suas práticas de postagem na comunidade virtual ( $\mathrm{H} 05)$.

Do ponto de vista social, em relação ao vértice $A$, Horácio apresenta seus valores de aprendiz, destacando os deveres individuais e coletivos acerca das atividades de aprendizagem, realizadas na comunidade virtual (H04).

O Quadro 2 sintetiza a distribuição dos relatos de Horácio no vértice $A$, segundo as relações epistêmicas, pessoais e sociais e as categorias de Lévy (1999).

Quadro 2 - Distribuição dos relatos de Horácio no vértice A: aprendiz Horácio

\begin{tabular}{|c|c|c|c|c|c|}
\hline $\begin{array}{l}\text { Categorias de Lévy } \\
\text { Dimensões da aprendizagem }\end{array}$ & Técnicas & Práticas & Atitudes & $\begin{array}{c}\text { Modos de } \\
\text { pensar }\end{array}$ & Valores \\
\hline Epistêmica & & $\mathrm{H} 02, \mathrm{H} 03, \mathrm{H} 11$ & & $\mathrm{H} 14$ & \\
\hline Pessoal & & $\mathrm{H} 01, \mathrm{H} 05$ & & & \\
\hline Social & & & & & $\mathrm{H} 04$ \\
\hline
\end{tabular}

Fonte: elaborado pelos autores.

Como podemos observar, os relatos de Horácio sobre sua aprendizagem (vértice A), incidiram principalmente na linha epistêmica e na coluna das práticas, com ausência de incidência na coluna das técnicas e das atitudes. 


\section{Vértice S: saber}

Do ponto de vista epistêmico, ao expor seus comentários relativos ao vértice S, Horácio traz suas compreensões e reflexões indicando o domínio das técnicas necessárias para realizar os estudos na EaD, entre elas: a navegação na Web; os downloads de arquivos; a edição de planilhas, imagens, em softwares especializados; as normas específicas para a padronização de trabalhos acadêmicos (H13).

Tanto do ponto de vista pessoal quanto do ponto de vista social, com relação ao vértice saber, na ocasião da entrevista não houve comentários do depoente. $A$ distribuição a respeito desse vértice é apresentada no Quadro 3.

Quadro 3 - Distribuição dos relatos de Horácio no vértice S: saber, cibercultura

\begin{tabular}{|l|c|c|c|c|c|}
\hline \multicolumn{1}{|c|}{ Categorias de Lévy } & Técnicas & Práticas & Atitudes & $\begin{array}{c}\text { Modos de } \\
\text { pensar }\end{array}$ & Valores \\
\hline Dimensões da aprendizagem & & $\mathrm{H} 13$ & & & \\
\hline Epistêmica & & & & & \\
\hline Pessoal & & & & & \\
\hline Social & & & & \\
\hline
\end{tabular}

Fonte: elaborado pelos autores.

Com relação ao vértice Saber, a incidência dos relatos de Horácio foi menor, com apenas um registro na linha epistêmica, na coluna das técnicas.

\section{Vértice F: fonte de saber}

Apresentamos, por fim, a distribuição dos relatos de Horácio com relação ao vértice $F$ (fonte de saber). Do ponto de vista epistêmico, Horácio expressa compreensões e reflexões a respeito das práticas exercidas pelo professor para a monitoria da comunidade virtual (H06), e comenta a respeito dos modos de pensar, sobre as colaborações que a tal comunidade proporcionou para sua aprendizagem $(\mathrm{H} 08, \mathrm{H} 12)$.

No que diz respeito ao ponto de vista pessoal, Horácio expressa sentimentos que relatam frustrações e desmotivações, causadas, segundo ele, por determinadas práticas de postagens realizadas pelos integrantes da comunidade virtual (H09).

Considerando a linha social, Horácio indica valores negativos, os quais não deixam de ser valores, e que relatam sobre aquilo/aquele que atrapalha a aprendizagem, ao comentar a respeito dos conteúdos de perguntas apresentadas pelos integrantes na comunidade virtual (H07); e valores positivos, quando relata a respeito do serviço de busca Google (H15). Também complementa, informando sobre atitudes positivas (que auxiliam a aprendizagem), acerca de situações de tensão com os demais integrantes da comunidade virtual (H10).

A síntese da distribuição dos relatos acerca do vértice F é exposta no Quadro 4. 
Quadro 4 - Distribuição dos relatos de Horácio no vértice F: fonte de saber, EaD no ciberespaço

\begin{tabular}{|c|c|c|c|c|c|}
\hline $\begin{array}{c}\text { Categorias de Lévy } \\
\text { Dimensões da aprendizagem }\end{array}$ & Técnicas & Práticas & Atitudes & Modos de pensar & Valores \\
\hline Epistêmica & & H06 & & $\mathrm{H} 08, \mathrm{H} 12$ & \\
\hline Pessoal & & H09 & & & \\
\hline Social & & & $\mathrm{H} 10$ & & $\mathrm{H} 07, \mathrm{H} 15$ \\
\hline
\end{tabular}

Fonte: elaborado pelos autores.

Nesse caso, observamos que houve uma distribuição mais uniforme tanto nas linhas quanto nas colunas, com ausência de incidência na coluna das técnicas.

\section{Distribuição Geral na Configuração de Aprendizagem}

A partir do exposto, podemos agrupar os dados dos Quadros 2, 3 e 4, e analisar a distribuição dos relatos de Horácio pelos três vértices, no Quadro 5.

Quadro 5 - Distribuição dos relatos de Horácio na configuração de aprendizagem

\begin{tabular}{|l|c|c|c|c|c|c|}
\hline \multicolumn{1}{|c|}{ Categorias de Lévy } & Técnicas & Práticas & Atitudes & $\begin{array}{l}\text { Modos de } \\
\text { pensar }\end{array}$ & Valores & Totais \\
\hline Dimensões da aprendizagem & $\mathrm{H} 13$ & $\begin{array}{l}\mathrm{H} 02, \mathrm{H} 03, \\
\mathrm{H} 11 ; \mathrm{H} 06 \\
\mathrm{H} 01, \mathrm{H} 05 ; \\
\mathrm{H} 09\end{array}$ & & $\begin{array}{l}\mathrm{H} 14 ; \mathrm{H} 08, \\
\mathrm{H} 12\end{array}$ & $8(53 \%)$ \\
\hline Epistêmica & & & $\mathrm{H} 10$ & & $\mathrm{H} 04 ; \mathrm{H} 07$, & $4(27 \%)$ \\
\hline Social & & & $\mathrm{H} 15$ & $4(20 \%)$ \\
\hline Totais & $1(7 \%)$ & $7(46 \%)$ & $1(7 \%)$ & $3(20 \%)$ & $3(20 \%)$ & $15(100 \%)$ \\
\hline
\end{tabular}

Fonte: elaborado pelos autores.

O Quadro 5 caracteriza a aprendizagem de Horácio sobre a cibercultura, com base nos 15 relatos realizados por ele. Podemos observar que, sob leitura vertical (categorias de Lévy), houve incidência de relatos em todas as colunas do Quadro 5, com predominância na aprendizagem do conjunto das práticas (46\%), seguida pelos modos de pensar (20\%) e valores (20\%). Pela leitura horizontal do quadro (dimensões da aprendizagem), pode-se notar que os relatos foram na maioria do tipo epistêmicos (53\%), embora tenham incidido na dimensão social (27\%) e pessoal (20\%). Por conseguinte, a aprendizagem de Horácio pode ser caracterizada como tendo sido, principalmente, do tipo epistêmico-prática.

Do ponto de vista epistêmico, Horácio apresenta suas reflexões e compreensões a respeito das práticas, modos de pensar e técnicas empregadas em sua aprendizagem da cibercultura. Com relação ao aprendizado da cibercultura a respeito das práticas, Horácio menciona: o acesso às aulas no AVA; a resolução de exercícios on-line; atividades de leitura e pesquisas na Web; participação e as postagens na comunidade virtual; atividades relativas à elaboração de trabalhos acadêmicos, à distância; bem como, as práticas exercidas pelo professor para a monitoria da comunidade virtual.

Considerando tais relações epistêmico-práticas, ao retomarmos as informações sobre o modelo pedagógico adotado pela IES do aprendiz, podemos observar que as 
relações fazem referência a elementos do modelo pedagógico, e às linhas de força que o compõem o primado da $\mathrm{EaD}$, os quais remetem à forma assíncrona utilizada pelo aprendiz e demais envolvidos, para a realização das atividades de aprendizagem no ciberespaço. Por conseguinte, ao vincular as relações do aprendiz ao modelo pedagógico, ratificamos Behar (2009), quando a autora afirma que o modelo pedagógico para a EaD se concretiza nas interações do triângulo professor/aluno/ objeto de estudo; e que os sujeitos agem de acordo com o modelo definido.

De modo específico, as relações epistêmico-práticas do aprendiz fazem referência aos aspectos organizacionais do modelo pedagógico, a respeito da comunidade virtual e dos papéis dos alunos e do tutor ( $\mathrm{H} 06, \mathrm{H} 11)$; aos aspectos metodológicos acerca das atividades e da interação com os recursos utilizados (H03); aos aspectos tecnológicos relativos à funcionalidade do AVA (H02) e à comunicação assíncrona no fórum de discussão (H06); e a respeito das estratégias implementadas para aplicação da arquitetura pedagógica do modelo - as comunidades virtuais de aprendizagem (H11) e o processo de tutoria pela internet (H06).

Sobre o primado da EaD, tais relações de Horácio remetem a três das quatro linhas de força: à aprendizagem centrada no aluno, no que se refere às situações de ensino que promovem a autonomia ( $\mathrm{H} 02, \mathrm{H} 03)$, criatividade $(\mathrm{H} 11)$, capacidade de monitorar sua aprendizagem (H02), e a interação entre os estudantes (H06, H11); à flexibilidade, acerca da possibilidade de aprender em qualquer lugar e horário (H02, H03); à interação aprendiz-aprendiz (H11) e interação aprendiz-tutor (H06).

Por fim, considerando que o ciberespaço é o meio no qual o triângulo da Figura 2 está inserido, podemos corroborar com Arruda e Passos (2015), quando os autores argumentam que, sob o conceito de configurações de aprendizagem, o tipo de fonte (F) depende do meio no qual a estrutura está inserida. Neste estudo, consideramos como meio, exclusivamente, o ciberespaço, por conseguinte, a fonte de saber identificada no triângulo foi a realizada sob as condições da EaD.

\section{Considerações Finais}

Neste artigo estudamos a aprendizagem de um sujeito sobre a cibercultura, em uma configuração de aprendizagem cuja fonte foi a EaD no ciberespaço. A caracterização da aprendizagem consistiu em inserir os relatos do aprendiz em quadros constituídos por colunas especificadas pelas cinco categorias de Lévy (1999) (técnicas, práticas, atitudes, modos de pensar e valores), e por linhas correspondentes às três dimensões da aprendizagem (epistêmica, pessoal, e social).

Com base nesse instrumento, verificamos que a aprendizagem sobre a cibercultura foi, principalmente, do tipo epistêmico-prática, acerca de relações que fazem referência aos elementos do modelo pedagógico e das linhas de força que compõe o primado da EaD. Esses elementos remetem à modalidade $100 \%$ on-line, e, por conseguinte, à forma assíncrona de comunicação e de realização das demais atividades.

Os dados sugerem que na atual geração da EaD, quanto mais atividades de aprendizagem forem realizadas no ciberespaço, e/ou quanto mais assíncrona a aprendizagem (pois a forma assíncrona nessa geração remete exclusivamente ao ciberespaço), mais relações epistêmico-práticas o aprendiz estabelece com a 
cibercultura. Afinal, a cibercultura é a cultura que oferece elementos para a participação ativa dos integrantes no ciberespaço (LEVY, 1999, 2009).

Em vista disso, as caracterizações que realizamos motivam-nos a ampliar as investigações a respeito das relações com a cibercultura, no ciberespaço, tendo como sujeitos de pesquisa outros aprendizes de cursos de graduação, na modalidade EaD $100 \%$ on-line e sujeitos de graduação na EaD semipresencial.

Por todo o exposto, consideramos que os resultados aqui apresentados podem ser úteis nas discussões acerca do ensino e da aprendizagem na EaD; da natureza da aprendizagem por meio do uso de tecnologias digitais; da participação da cibercultura nos processos de formação. E, podem contribuir para o planejamento e diagnóstico do ensino-aprendizagem na EaD, por meio de análises das relações com o saber.

No campo das pesquisas em Educação, a partir dos resultados, torna-se, também, possível vislumbrar possibilidades para estudos futuros a respeito: das configurações de aprendizagem em situações de uso da tecnologia de realidade aumentada (RA); da formação de professores mediada pela cibercultura; da relação epistêmica com o saber e o princípio da inteligência coletiva na EaD; das implicações que as atividades realizadas off-line têm para o desenvolvimento da cibercultura na Web.

\section{Agradecimentos}

Ao Conselho Nacional de Desenvolvimento Científico e Tecnológico (CNPq), e à Coordenação de Aperfeiçoamento de Pessoal de Nível Superior (CAPES), pelo apoio financeiro.

\section{Referências}

ALVES, J. R. M. A história da educação a distância no Brasil. Educação em Foco, Rio de Janeiro, ano 16, n. 82, 2007. Disponível em: http://www.ipae.com.br/pub/pt/cme/cme_82/index.htm. Acesso em: 26 fev. 2021.

ALVES, L. Educação a distância: conceitos e história no Brasil e no mundo. Revista Brasileira de Aprendizagem Aberta e a Distância, São Paulo, v. 10, p. 83-92, 2011. DOI: https://doi.org/10.17143/ rbaad.v10i0.235.

ALVES, S. R. Dicionário de tecnologia educacional: terminologia básica apoiada por micromapas. São Paulo: PerSe, 2011.

ARRUDA, S. M.; LIMA, J. P. C.; PASSOS, M. M. Um novo instrumento para a análise da ação do professor em sala de aula. Revista Brasileira de Pesquisa em Educação em Ciências, Belo Horizonte, v. 11, n. 2, p. 139-160, 2011. Disponível em: https://periodicos.ufmg.br/index.php/rbpec/article/ view/4200. Acesso em: 26 fev. 2021.

ARRUDA, S. M.; PASSOS, M. M. A relação com o saber na sala de aula. In: COLÓQUIO INTERNACIONAL EDUCAÇÃO E CONTEMPORANEIDADE, 9., 2015, Aracaju. Anais [...]. Aracaju: UFS, 2015. p. 1-14. Disponível em: http://educonse.com.br/ixcoloquio/arruda_passos2.pdf. Acesso em: 26 fev. 2021.

ARRUDA, S. M.; PASSOS, M. M. Instrumentos para a análise da relação com o saber em sala de aula. Revista de Produtos Educacionais e Pesquisas em Ensino, Cornélio Procópio, v. 1, n. 2, p. 95-115, 2017. Disponível em: http://seer.uenp.edu.br/index.php/reppe/article/view/1213/811. Acesso em: 26 fev. 2021. 
ARRUDA, S. M.; PORTUGAL, K. O.; PASSOS, M. M. Focos da aprendizagem: revisão, desdobramentos e perspectivas futuras. Revista de Produtos Educacionais e Pesquisas em Ensino, Cornélio Procópio, v. 2, n. 1, p. 91-121, 2018. Disponível em: http://seer.uenp.edu.br/index.php/ reppe/article/view/1298. Acesso em: 26 fev. 2021.

BEHAR, P. A. Modelos pedagógicos em educação a distância. In: BEHAR, P. A. (org.). Modelos pedagógicos em educação a distância. Porto Alegre: Artmed, 2009. p. 15-32.

BOGDAN, R. C.; BIKLEN, S. K. Investigação qualitativa em educação: uma introdução à teoria e aos métodos. Porto: Porto Editora, 1994.

BRASIL. Decreto n० 9.057, de 25 de maio de 2017. Regulamenta o art. 80 da Lei no 9.394, de 20 de dezembro de 1996, que estabelece as diretrizes e bases da educação nacional. Diário Oficial da União: seção 1, Brasília, ed. 100, p. 1, 26 maio 2017. Disponível em: https://cutt.ly/2IOMj9n. Acesso em: 26 fev. 2021.

CHARLOT, B. Da relação com o saber: elementos para uma teoria. Porto Alegre: Artmed, 2000.

ENCYCLOPEDIA Britannica. [2018]. Disponível em: https://www.britannica.com. Acesso em: 15 set. 2019.

FERIGATO, S. H.; SILVA, C. R.; LOURENCO, G. F. Cyberculture and occupational therapy: creating connections. South African Journal of Occupational Therapy, Pretoria, v. 47, n. 2, p. 45-48, 2017. DOI: https://doi.org/10.17159/231-3833/1017/v47n2a8.

FIORENTINI, D.; LORENZATO, S. Investigação em educação matemática: percursos teóricos e metodológicos. 3. ed. Campinas: Autores Associados, 2012.

LÉVY, P. Cibercultura. São Paulo: Editora 34, 1999.

LÉVY, P. La mutation inachevée de la sphère publique. Signo y Pensamiento, Bogotá, v. 28, n. 54, p. 36-43, 2009. Disponível em: https://www.redalyc.org/articulo.oa?id=86011409002. Acesso em: 26 fev. 2021.

LOBATO, L.; KENKEL, K. M. A ciberguerra é moderna!: uma investigação sobre a relação entre tecnologia e modernização na guerra. Contexto Internacional, Rio de Janeiro, v. 37, n. 2, p. 629660, 2015. DOI: https://doi.org/10.1590/S0102-85292015000200010.

MACHADO, E. S.; ARRUDA, S. M.; PASSOS, M. M. A relação dos aprendizes com o saber e com as plataformas digitais sob o conceito de configurações de aprendizagem. In: CONGRESSO INTERNACIONAL DE ENSINO, 2., 2019, Cornélio Procópio. Anais [...].Cornélio Procópio: UENP, 2019. p. 2274-2283.

MICHAELIS. Moderno dicionário da língua portuguesa. [2018]. Disponível em: https://michaelis. uol.com.br/moderno/portugues/. Acesso em: 15 set. 2019.

NATIONAL RESEARCH COUNCIL. Learning science in informal environments: people, places, and pursuits. Washington: NRP, 2009.

SILVA, A. S. Teorias da aprendizagem na EaD: ideações de professores autores de material didático impresso. 2016. 128 f. Dissertação (Mestrado em Educação) - Faculdade de Educação, Universidade Federal de Uberlândia, Uberlândia, 2016.

VENDRUSCOLO, M. I.; BEHAR, P. A. Investigando modelos pedagógicos para educação a distância: desafios e aspectos emergentes. Educação, Porto Alegre, v. 39, n. 3, p. 302-311, 2016. DOI: https:// doi.org/10.15448/1981-2582.2016.3.20666.

WIENER, N. Cybernetics: or, control and communication in the animal and the machine. Cambridge, Mass: MIT Press, 1948.

WIENER, N. The human use of human beings: cybernetics and society. London: Free Association Books, 1989. 